\title{
Anemia among women of reproductive age: a cross sectional study in Sub district hospital, Akhnoor
}

\author{
Chandan Sharma $^{1}$, Ashima Badyal ${ }^{2 *}$ \\ ${ }^{1}$ Department of Medicine, Sub-District Hospital, Akhnoor, Distt. Jammu, Jammu and Kashmir, India \\ ${ }^{2}$ Department of Biochemistry, Government Medical College, Jammu, Jammu and Kashmir, India
}

Received: 01 June 2021

Accepted: 16 June 2021

\section{*Correspondence:}

Dr. Ashima Badyal,

E-mail: badyal.ashima@g mail.com

Copyright: $\odot$ the author(s), publisher and licensee Medip Academy. This is an open-access article distributed under the terms of the Creative Commons Attribution Non-Commercial License, which permits unrestricted non-commercial use, distribution, and reproduction in any medium, provided the original work is properly cited.

\begin{abstract}
Background: Anemia in pregnancy can increase the risk of having a pre-term delivery/babies, which may further lead to low birth weight and sometimes death. Anemia is more prevalent in Asia, with half of the all-anemic women living in Indian subcontinent itself. The objective of the study was to estimate the prevalence of anemia among women in the reproductive age group (15-49) in a rural population set up of Akhnoor.

Methods: A population based cross-sectional study was conducted in Sub district hospital, Akhnoor, Jammu, J and K, India, over a period of 6 months from September 2020 to February 2021, on a total of 320 women in the reproductive age group of 15 to 49 years.

Results: A total prevalence of 59.06\% was found with highest among pregnant females. Out of this total anemic patient $59.78 \%$ (113/189) were mild anemic, and 40.22\% (76/189) were either moderately anemic or severe. High prevalence of anemia was seen among illiterate women (68.89\%). Prevalence was also significantly associated to excessive/ scanty menstruation. Besides, menstrual cycle more than 35 days and less than 21 days were found to be at higher risk of anemia $(60.53 \%$ and $83.33 \%)$. Underweight women were also found at higher risk of anemia $(69.52 \%)$. Only 88 out of 320 women studied had completed the course of IFA tablets.

Conclusions: Several socio-demographic, menstrual, dietary, environmental, and behavioral factors were associated with anemia. Women of reproductive age should be motivated to include food fortification or iron supplementations in their diet.
\end{abstract}

Keywords: Anemia, Reproductive age, Iron supplementation

\section{INTRODUCTION}

In any community, mothers and children constitute a priority group. In developing countries, they comprise more than $70 \%$ of the population. In India, for example, women of the child bearing age, i.e., 15 to 49 years, constitute almost one-fourth of the total population. This reproductive age group also makes up a special risk group. During reproductive years, women are considered at risk of iron deficiency with repeated blood loss due to menstruation. ${ }^{1}$ Cause of more than $20 \%$ maternal deaths in
India is due to anemia. ${ }^{2}$ More than $50 \%$ of women don't have iron stores required during pregnancy. ${ }^{3}$ Therefore, the national health survey national family health survey (NFHS-3, 2005-2006), found prevalence of anemia at $53.3 \%$ among reproductive age group women of Tamil $\mathrm{Nadu}$ with the prevalence being slightly higher in rural than urban areas. ${ }^{4}$

Iron is one such mineral required by human body to carry out some essential functions. One of the basic functions that iron performs in our body is to transport oxygen from 
lungs to other cells by being an essential part of hemoglobin itself. Hemoglobin levels for healthy males (age 15 years of more) is $130 \mathrm{gm} / \mathrm{L}$, while for non-pregnant women (age 15 years or more) is $120 \mathrm{gm} / \mathrm{L}$. Anemia has been a major public health problem seen over the last few years now. It has been found that the most common nutrition deficiency throughout the globe is Irondeficiency. ${ }^{5}$ The common signs/symptoms of anemia are: lethargy feeling decreased immune function, inflamed tongue, headache, palpitations, dizziness, emotional instability, depression and restlessness. Iron deficiency is known to cause fatigue, decreased motor abilities, impaired memory and can cause delays in mental development. ${ }^{6}$ Anemia in pregnancy can increase the risk of having a pre-term delivery/babies, which may further lead to low birth weight and sometimes death. A preterm birth is one of the causes of infant mortality. ${ }^{7}$ Although iron deficiency is common among women of all nations, statistics show that it is more common among developing countries. Anemia is more prevalent in Asia, with half of the all-anemic women living in Indian subcontinent itself, where $88 \%$ of them develop anemia during pregnancy only. ${ }^{8}$

The objective of the study was to estimate the prevalence of anemia among women in the reproductive age group (1549 ) in a rural population set up of Akhnoor and to find out the association of certain socioeconomic and cultural factors with anemia.

\section{METHODS}

A population based cross-sectional study was conducted among the rural population of Akhnoor, over a period of 6 months from September 2020 to February 2021 in sub district hospital, Akhnoor. A total of 320 women in the reproductive age group of 15 to 49 years were studied. With assumed prevalence: $60 \%$ and keeping a margin of error up to $5 \%$ and confidence level at $95 \%$, the sample size worked out to be: 311 . This formed the bases of selection of 320 women in the age group of 15-49 years, using random sampling technique, out of the patients as well as the accompanying attendants attending the open patient department of sub district hospital Akhnoor, J and K. Ethical clearance was obtained from institutional ethical committee. The women were clinically examined for the presence of pallor in tongue, nails and the conjunctiva, blood pressure, and pulse rate, which were also recorded.

\section{Inclusion criteria}

All the study subjects being women in the age group of 15 to 49 years were included in the study.

\section{Exclusion criteria}

Children below the age of 15 years and women above 49 years and women with recently blood transfused or having chronic medical diseases, diagnosed with the haemoglobinopathies, and the bleeding disorders or the ante partum hemorrhage were excluded from the current study.

A detailed survey questionnaire, prepared for the purpose, was pre-tested among 20 women in the reproductive age group of 15-49 years under similar circumstances/ and locate as that of the main group, using randomization. The questionnaire included socio-demographic and cultural background, menstrual disorders, obstetric history, contraceptive practices, diet and personal hygiene, and environmental sanitation of the women. The purpose of the study was explained to the respondent individually and oral informed consent was obtained. Upon pretest the questionnaire was applied on the next 300 women selected. Anthropometric measurements, height and weight, and hemoglobin estimation of each woman were taken with the help of laboratory technician for estimating hemoglobin level. Estimation of hemoglobin level was done by finger prick method for collecting blood using sterile single use disposable lancet and diagnosis of anaemia was estimated by using the standard peripheral blood smear examination and shale's acid haemitin method of hemoglobin estimation. The anthropometric data collected included height and weight, with same, scales and weighing machines used for all the women studied.

The data entry and analysis were done using the MS excel 2010. Statistical descriptions like percentage and Mean \pm Standard deviation were used. Analysis was done using Chi-square test was performed and $\mathrm{p}<0.05$ was taken as statistically significant.

\section{RESULTS}

A total number of cases having any kind of anemia were found to be 189, giving a total prevalence of $59.06 \%$. However, this was highest among pregnant females. $8.33 \%$ of pregnant females had severe type of anemia, against only $4.23 \%$ among non-pregnant females. Total number of cases with mild, moderate or severe type of Anemia were found to be $189(189 / 320=59.06 \%)$ Out of this total anemic patient $59.78 \%(113 / 189)$ were mild anemic, and $40.22 \%$ (76/189) were either moderately anemic or severe (Table 1).

Certain socioeconomic factors such as education and menstrual and obstetric factors such as extended length of menstrual cycle, Pelvic inflammatory disease, contraception use, pregnancy, and iron and folic acid (IFA) use, were found to have some important association with anemia. Women who were underweight, taking vegetarian diet were found to have statistically significant association with anemia. Scanty as well as excessive menstrual bleeding had clear and significant association with anemia among women of reproductive age as shown in the Table 2 . 
Table 1: Prevalence of anemia in pregnant and non-pregnant women in the reproductive age group.

\begin{tabular}{|lllllll|}
\hline Types of anemia & Pregnant & Percent $(\boldsymbol{\%})$ & Non-pregnant & Percent $(\boldsymbol{\%})$ & Total & Percent $(\%)$ \\
\hline No & 11 & 30.56 & 120 & 42.25 & 131 & 40.94 \\
\hline Mild & 12 & 33.33 & 101 & 35.56 & 113 & 35.31 \\
\hline Moderate & 10 & 27.78 & 51 & 17.96 & 61 & 19.06 \\
\hline Severe & 3 & 8.33 & 12 & 4.23 & 15 & 4.69 \\
\hline Total & 36 & 100 & 284 & 100 & 320 & 100 \\
\hline
\end{tabular}

Table 2: Association of anemia to various factors and variables.

\begin{tabular}{|c|c|c|c|c|c|}
\hline Variables & $\begin{array}{l}\text { No of cases } \\
\text { with anemia }\end{array}$ & $\begin{array}{l}\text { No of cases without } \\
\text { anemia }\end{array}$ & Total & $\begin{array}{l}\text { Prevalence } \\
(\%)\end{array}$ & $\begin{array}{l}\text { P value by } \\
\text { Chi-test }\end{array}$ \\
\hline \multicolumn{6}{|l|}{ Age groups (Years) } \\
\hline $15-19$ & 17 & 10 & 27 & 62.96 & \multirow{4}{*}{0.9669} \\
\hline $20-29$ & 71 & 51 & 122 & 58.20 & \\
\hline $30-39$ & 69 & 49 & 118 & 58.47 & \\
\hline $40-49$ & 32 & 21 & 53 & 60.38 & \\
\hline \multicolumn{6}{|l|}{ Occupation } \\
\hline Skilled & 7 & 6 & 13 & 53.85 & \multirow{3}{*}{0.8184} \\
\hline Semi-skilled & 104 & 75 & 179 & 58.10 & \\
\hline Unskilled & 78 & 50 & 128 & 60.94 & \\
\hline \multicolumn{6}{|l|}{ Education } \\
\hline Illiterate & 31 & 14 & 45 & 68.89 & \multirow{2}{*}{0.1482} \\
\hline Literate & 158 & 117 & 275 & 57.45 & \\
\hline \multicolumn{6}{|l|}{ Marital status } \\
\hline Married (currently) & 152 & 102 & 254 & 59.84 & \multirow{2}{*}{0.5777} \\
\hline Unmarried/ Others & 37 & 29 & 66 & 56.06 & \\
\hline \multicolumn{6}{|l|}{ Religion } \\
\hline Hindu & 89 & 57 & 146 & 60.96 & \multirow{4}{*}{0.9171} \\
\hline Muslim & 68 & 50 & 118 & 57.63 & \\
\hline Sikh & 20 & 16 & 36 & 55.56 & \\
\hline Christian & 12 & 8 & 20 & 60.00 & \\
\hline \multicolumn{6}{|l|}{ Height } \\
\hline$<4^{\prime} 9^{\prime \prime}$ & 13 & 13 & 26 & 50.00 & \multirow{3}{*}{0.2256} \\
\hline $4^{\prime} 9^{\prime \prime}$ to $5^{\prime} 2^{\prime \prime}$ & 134 & 98 & 232 & 57.76 & \\
\hline$>5^{\prime} 2^{\prime \prime}$ & 42 & 20 & 62 & 67.74 & \\
\hline \multicolumn{6}{|l|}{ Weight } \\
\hline Overweight & 36 & 27 & 63 & 57.14 & \multirow{3}{*}{$0.0241 *$} \\
\hline Normal & 80 & 72 & 152 & 52.63 & \\
\hline Underweight & 73 & 32 & 105 & 69.52 & \\
\hline \multicolumn{6}{|l|}{ Menstrual bleeding } \\
\hline Excessive & 41 & 17 & 58 & 70.69 & \multirow{3}{*}{$0.0042^{*}$} \\
\hline Scanty & 39 & 15 & 54 & 72.22 & \\
\hline Normal & 109 & 99 & 208 & 52.40 & \\
\hline \multicolumn{6}{|c|}{ Length of menstrual cycle } \\
\hline Normal & 146 & 112 & 258 & 56.59 & \multirow{3}{*}{$0.0381^{*}$} \\
\hline$<21$ days & 20 & 4 & 24 & 83.33 & \\
\hline$>35$ days & 23 & 15 & 38 & 60.53 & \\
\hline \multicolumn{6}{|l|}{ Pregnancy status } \\
\hline Pregnant & 25 & 11 & 36 & 69.44 & \multirow{2}{*}{0.1787} \\
\hline Non- pregnant & 164 & 120 & 284 & 57.75 & \\
\hline \multicolumn{6}{|l|}{ PID } \\
\hline Yes & 37 & 27 & 64 & 57.81 & \multirow{2}{*}{0.8201} \\
\hline No & 152 & 104 & 256 & 59.38 & \\
\hline
\end{tabular}




\begin{tabular}{|c|c|c|c|c|c|}
\hline Variable & $\begin{array}{l}\text { No of cases } \\
\text { with anemia }\end{array}$ & $\begin{array}{l}\text { No of cases without } \\
\text { anemia }\end{array}$ & Total & $\begin{array}{l}\text { Prevalence } \\
(\%)\end{array}$ & $\begin{array}{l}\text { P value by } \\
\text { Chi-test }\end{array}$ \\
\hline \multicolumn{6}{|l|}{ Abortions } \\
\hline Yes & 22 & 9 & 31 & 70.97 & \multirow{2}{*}{0.1560} \\
\hline No & 167 & 122 & 289 & 57.79 & \\
\hline \multicolumn{6}{|l|}{ IFA tablets } \\
\hline Completed & 45 & 43 & 88 & 51.14 & \multirow{2}{*}{0.0758} \\
\hline Not Completed & 144 & 88 & 232 & 62.07 & \\
\hline \multicolumn{6}{|c|}{ Contraception used } \\
\hline Used & 60 & 50 & 110 & 54.55 & \multirow{2}{*}{0.2343} \\
\hline Not Used & 129 & 81 & 210 & 61.43 & \\
\hline \multicolumn{6}{|l|}{ Diet } \\
\hline Vegetarian & 93 & 60 & 153 & 60.78 & \multirow{2}{*}{0.5488} \\
\hline Mixed & 96 & 71 & 167 & 57.49 & \\
\hline \multicolumn{6}{|l|}{ No of issues } \\
\hline$\geq 2$ & 73 & 41 & 153 & 60.78 & \multirow{2}{*}{0.3603} \\
\hline$\leq 1$ & 116 & 90 & 167 & 57.49 & \\
\hline
\end{tabular}

$* \mathrm{P}<0.05=$ significant.

\section{DISCUSSION}

Anemia, as defined by world health organization is a condition in which the hemoglobin concentration in the blood is below a defined level, resulting in a reduced oxygen carrying capacity of red blood cells. ${ }^{9}$ Among poor nations, pregnant women and children are the most anemic population group and also don't have much access to interventions and other health services. Established prevalence of any kind of anemia among women of reproductive age in India is more than $55 \%$ with $20-40 \%$ of maternal deaths are due to anemia. ${ }^{10}$

A study conducted by Nidhi et al on 500 female patients of age group 10-35 years, in Jammu and Kashmir, India, in 2019, found that mild anemia (Hb: 10-12 g/dl) was prevalent at $74-79 \%$ and Moderate anemia (Hb: $8-10 \mathrm{~g} / \mathrm{dl}$ ) was prevalent at $10-14 \%$ out of total anemic patients, with highest $\mathrm{Hb}$ recorded was $12.4 \mathrm{~g} / \mathrm{dl} .{ }^{11}$ In our case, Mild anemia was prevalent at $59.78 \%$ and moderate/ severe was prevalent at $40.22 \%$ among total anemic patients. The geographical and demographically different set of populations could be differentiating factor here. At the same time in our study, distribution of anemia by the age did not show any statistical significance, however, there were other contributing factors relevant to the age of the female that enhanced the risk of anemia among female of lower age. High prevalence of anemia was seen among illiterate women $(68.89 \%)$ when compared to literate women $(57.45 \%)$ and similarly seen in other studies in India as well. ${ }^{12}$ This revealed that women's educational status plays an important role in the prevalence of anemia in the reproductive age group, which can be attributed to better knowledge of literate women on the importance of taking iron rich diet and theimportance of personal hygiene and environmental sanitation. Studies have also shown that mean hemoglobin level is higher in post-menopausal women. ${ }^{13}$ This is primarily because of no menstrual loss in menopausal women, pregnancy, and other related factors. But our study as pertained to completely rural set up, most of the women in the age-group studied had no insight into this status of their reproductive health and therefore the question was dropped from the survey set after pre-test. As our results showed more than $70 \%$ prevalence of excessive/scanty menstruation, it is clear that they are related to anemia in women. Increased loss of iron, through blood loss, is the main cause of anemia in women with excessive menstrual bleeding. Similarly, malnutrition or existing anemia often becomes the main cause for anemia in women with scanty menstruation. Theresa et al also showed that due to blood loss from menstruation in reproductive years, women are at a high risk of iron deficiency anemia. ${ }^{14}$

Women who used any type of contraception were seemingly at a lower risk of anemia $(54.55 \%)$ when compared to others not using contraceptive $(61.43 \%)$. Contraception may have been preventing excessive blood loss due to abortions and unwanted pregnancies. At the same time, menstrual cycle more than 35 days and less than 21 days were found to be at higher risk of anemia $(60.53 \%$ and $83.33 \%$ ) when compared to women who had normal menstrual cycle $(56.59 \%)$. Higher prevalence of anemia in first case could be due to under nutrition and already existing anemia, while in case of women who had menstrual cycle <21 days, a heavy menstrual blood loss, deficient dietary intake and increased need of iron could be leading to anemia. A similar set of findings has been reported by Monárrez-Espino et al. ${ }^{13}$ The problem of being underweight is found to aggravated this issue, as underweight women were found significantly at higher risk of anemia $(69.52 \%)$ when compared to women having normal weight $(52.63 \%)$ similar to other studies in Andhra Pradesh, India. ${ }^{15}$ Vegetarian diet also corresponded to higherrisk of anemia $(60.78 \%)$ than those taking vegetarian and non-vegetarian-mixed diet (57.49\%). Mehta et al reported a similar finding. This could be 
attributed to low dietary intake of iron in vegetative form by vegetarians. ${ }^{16}$

Females, who had completed the course of IFA tablets should be at lesser risk of anemia (51.14\%) when compared to women who did not complete the course (62.07\%) and this difference is important, but not significant enough. IFA tablets are meant to correct the iron depletion and restore the body iron stores. The more significant aspect over here is that only 88 out of 320 subjects studied had completed the course. There could have been more who had been on the way to completion. But still this number is quite low. WHO makes it mandatory to regularly supply of IFA tablets to adolescent girls and pregnant women from $24^{\text {th }}$ week onwards till 12 weeks of postpartum period. With 153 women having more than 1 issue in their life time and an additional 36 women being pregnant, such a low number of only 88 subjects having completed this mandatory course does not augur well with the implementation of such an important scheme. Preventive measures such as IFA supplementation for adolescent girls, improving the standard of living and environmental conditions can reduce the burden of this disease. Health education has to be imparted covering all aspects of adequate dietary intake of iron, personal and environmental hygiene and seeking early medical help before a moderate case becomes severe.

The limitation of the study was that it was conducted on the females visiting the OPD of SDH Akhnoor, where as a lot of women populations may not be visiting such health institutions for routine checkup or seeking advice in connection to their reproductive health care. Moreover, it was quite difficult to directly enquire about such matters from females from rural background with lots of social taboos in this regard. Similar surveys and investigations in an urban set up like Jammu may generate more data relevant to such prevalence studies.

\section{CONCLUSION}

It can be interpreted that socio-demographic, menstrual, obstetric, contraceptive, dietary, environmental, and behavioral factors were associated with anemia in reproductive age group. A very high prevalence of anemia at $69.44 \%$, with 25 out of 36 pregnant women showing some kind of anemia, indicates a poor response to the national and WHO programmes to address this problem. All practitioners should motivate women patients in such an age group for food fortification or iron supplementations in addition to balanced diet.

\section{Funding: No funding sources}

Conflict of interest: None declared

Ethical approval: The study was approved by the Institutional Ethics Committee

\section{REFERENCES}

1. Dutta DC. Text Book of Gynaecology. $4^{\text {th }}$ ed. Calcutta: New Central Publication. 2005;74-80:17586.

2. Royston E. The prevalence of nutritional anaemia in women in developing countries: A critical review of available information. World Health Stat Q. 1982;35(2):52-91.

3. Perry GS, Yip R, Zyrkowski C. Nutritional risk factors among low-income pregnant US women: The Centers for Disease Control and Prevention (CDC) pregnancy nutrition surveillance system, 1979 through 1993. Semin Perinatol. 1995;19(3):211-21.

4. National Family Health Survey (NFHS)-3 (20052006). Tamil Nadu: Fact sheet. 2006.

5. Milman N. Anemia- still a major health problem in many parts. Ann Hematol. 2011;90:369-77.

6. Yanovich R, Mrekel D, Israeli E. Anemia, iron deficiency and stress fractures in female combatants during 16 months. J strength Cond Res. 2011;25:3412-21.

7. Aspuru K, Villa C, Bermejo F, Herrero. Optimal management of iron deficiency anemia due to poor dietry intake. Int J Gen Med. 2011;4:741-50.

8. Siddiqui MS, Siddiqui MK. Public health significance of iron deficiency anemia. Pak armed forces Med J. 2008;58:3.

9. Nutritional anemias. Report of a WHO group of experts. World Health Organ Tech Rep Ser. 1972;503:1-29.

10. International Institute for Population Sciences (IIPS) and Macro International. National Family Health Survey (NFHS-3), 2005-06: India: 2007;1.

11. Nidhi K, Mandeep K. Hemoglobin status and prevalence of anemia among women of Jammu and Kashmir population: A cross sectional study. Int $\mathbf{J}$ Med Health Res. 2019;5(3):1-2.

12. National Family Health Survey (NFHS)-3 (20052006). India: Fact sheet. 2007.

13. Monárrez-Espino J, Martínez H, Greiner T. Iron deficiency anemia in Tarahumara women of reproductive-age in northern Mexico. Salud Publica Mex. 2001;43(5):392-401.

14. Scholl TO. Iron status during pregnancy: Setting the stage for mother and infant. Am $\mathbf{J}$ Clin Nutr. 2005;81(5):1218S-22.

15. Bentley ME, Griffiths PL. The burden of anemia among women in India. Eur $\mathrm{J}$ Clin Nutr. 2003;57(1):52-60.

16. Mehta BC. Wide spread iron deficiency anemia in India-its causes. Indian J Med Sci. 1982;36(5-6):10812.

Cite this article as: Sharma C, Badyal A. Anemia among women of reproductive age: a cross sectional study in Sub district hospital, Akhnoor. Int J Reprod Contracept Obstet Gynecol 2021;10:2662-6. 